\title{
MIRADAS OBLICUAS: INFANCIAS, PAISAJES Y COMUNIDADES INTERRUMPIDAS EN EL CINE DE DOMINGA SOTOMAYOR
}

Oblique glances: children, landscape and interrupted communities in the cinema of Dominga Sotomayor

\author{
MARIANO SEBASTIAN VELIZ \\ UNIVERSIDAD DE BUENos Aires (AREGENTINA) \\ marianoveliz@gmail.com http: //orcid.org/0000-0002-3938-3622
}

Mercedes Alonso

UNIVERSIDAD DE BUENOS AIRES-UNIVERSIDAD NACIONAL DE LAS ARTES (ARgENTINA)

meralonsa@gmail.com http://orcid.org/0000-0002-9309-6464

MARIELA STAUDE

Universidad DE Buenos Aires (ARgentina)

marielastaude@gmail.com http://orcid.org/0000-0002-0711-9034

RECIBIDO: 3 DE JUNIO DE 2020

ACEPTADO: 21 DE OCTUBRE DE 2020

RESUMEN: Dominga Sotomayor propone, en De jueves a domingo (2012), Mar (2014) y Tarde para morir joven (2018), exploraciones de la intimidad de una familia, una pareja y una comunidad. En estos acercamientos, la intimidad se configura en grados variables de tensión con el afuera y lo público. En estas oscilaciones se pone en evidencia una de las características más recurrentes y estudiadas del cine chileno contemporáneo: la conversión de la intimidad en el locus sobre el que se proyectan, de manera indirecta, los conflictos del pasado y el presente. Este artículo considera la forma en que el cine de Sotomayor se inscribe en el panorama actual del cine chileno y, a través de él, en su escenario socio político desde un análisis que atiende a tres problemáticas interrelacionadas: las formas narrativas y sensibles de representación, su articulación desde posiciones -narrativas, espaciales y sensoriales- juveniles y la construcción del paisaje en interacción entre entornos naturales y los sujetos y que los ocupan y circulan por ellos.

PALABRAS CLAVE: cine chileno, intimidad, juventud, paisaje.

ABSTRACT: In De jueves a domingo (2012), Mar (2014) and Tarde para morir joven (2018), Dominga Sotomayor explores the intimacy of a family, a couple and a community. In these approaches, intimacy establishes varying degrees of tension with the outside and the public. These oscillations highlight one of the most frequent and repeatedly studied characteristics of contemporary Chilean cinema: the transformation of intimacy into the locus where the conflicts of the past and the present are indirectly projected. This article considers the way in which Sotomayor's cinema is inscribed in the current panorama of Chilean cinema and, through it, in its socio-political scenario. It aims at doing so analyzing three interrelated problems: the narrative and sensitive forms of representation, their articulation from the narrative, spatial and sensorial positions of the young and the construction of landscape through the interaction between natural environments and subjects that occupy and move through them.

KEY WORDS: Chilean cinema, intimacy, youth, landscape. 


\section{INTRODUCCIÓN}

Dominga Sotomayor propone, en De jueves a domingo (2012), Mar (2014) y Tarde para morir joven (2018), exploraciones de la intimidad de una familia, una pareja y una comunidad. En estos acercamientos, la intimidad se configura en grados variables de tensión con el afuera y lo público. En estas oscilaciones se pone en evidencia una de las características más recurrentes y estudiadas del cine chileno contemporáneo: la conversión de la intimidad en el locus sobre el que se proyectan, de manera indirecta, los conflictos del pasado y el presente. Entre las herencias de la dictadura y los embates del neoliberalismo, la domesticidad emerge como territorio donde se inscriben los dilemas políticos y sociales. En cada una de estas películas, estas dimensiones irrumpen de modos distintos, pero siempre abordadas desde las perspectivas de niños y adolescentes. Ellos son los portadores de la mirada y en sus experiencias transicionales se marcan la variabilidad de los roles (en el orden familiar y comunitario), las relaciones de poder y la irrupción de la historia. En los tres casos, al mismo tiempo, se imbrican las modificaciones de los personajes y los viajes o desplazamientos que emprenden. En estas travesías, de muy diversas índoles, se convierten en espectadores, habitantes y constructores de paisajes. En estas tensiones entre la intimidad y la política, la infancia y la adolescencia, la naturaleza y el paisaje se construye una filmografía en movimiento. Sotomayor configura, en el panorama actual del cine chileno, un tejido de películas con recurrencias y diferencias, siempre atento a la materialidad de las historias y a las tensiones epocales.

\section{PERSPECTIVAS OBLICUAS: INTIMIDAD E HISTORIA}

En el comienzo de De jueves a domingo, la escena de una familia preparando el vehículo para partir de viaje se percibe desde detrás de la ventana del dormitorio de los niños. La situación se construye con los susurros de los padres al levantarlos, la luz difusa del amanecer, los rostros adivinados en la penumbra, los movimientos ralentizados del despertar, las palabras apenas audibles de los diálogos entre los adultos. Los gestos y las acciones que articulan ese fin de semana compartido, el último antes de la inminente separación de la pareja, se observan de manera atenta y, al mismo tiempo, desprevenida. Atenta porque se trata de un registro minucioso de aquellos elementos que parecen posicionados en el límite de lo insignificante. Desprevenida, porque resulta a su vez sometida a una lógica del azar en la que no todos los componentes de la puesta en escena se encuentran programados. Esta aparición de lo azaroso y lo imprevisto acerca la película a ciertas concepciones del cine documental ${ }^{1}$.

Esta búsqueda emprendida por Dominga Sotomayor podría inscribirse en el marco de lo que Carolina Urrutia concibe como "cine centrífugo", una tendencia que habría irrumpido en

\footnotetext{
1 En "Documentando una realidad programada", un artículo publicado en 2005, antes del rodaje de sus cortos y largometrajes, Dominga Sotomayor manifiesta su interés en cierta tendencia del cine de ficción cercano al documental y emergente a posteriori de la expansión del rodaje en video digital. En ese cine resulta destacable la emergencia de lo cotidiano y lo imprevisible, la lógica del registro que ordena la puesta en escena, la conversión de la realidad en un set de filmación extendido, la desaparición del carácter informativo de los diálogos, la irrupción de lagunas significativas en la construcción de los personajes y las historias. Muchos de los elementos mencionados ocupan, como se verá, un lugar notable en su propia producción cinematográfica.
} 
Chile en el año 20052. En este cine, la predilección por los acontecimientos de la domesticidad familiar no debería confundirse con la elección de la desnarrativización. La melancolía ante la disolución de una pareja o la paulatina comprensión de la hija acerca de ese desenlace difícilmente puedan considerarse acciones desprendidas de conflicto. Sin embargo, sí se articula una modalidad de la mirada, con particular hincapié en la portada por niños y adolescentes, que desdramatiza la acción a través de la posición privilegiada asignada a situaciones que podrían considerarse menores, aunque funcionan como vía de entrada a la diégesis. No se trata solo de suprimir episodios de intensidad dramática a través de la recurrencia de la elipsis y el fuera de campo, sino también de configurar una percepción oblicua de la historia narrada. Oblicua en tanto su aproximación está siempre desviada, alejada de lo que podría ser concebido como el trazo directo de la dramaturgia clásica. La proliferación de sobre-encuadres, la obstaculización de la mirada a través de la sumatoria de objetos interpuestos, el acceso diferido a las situaciones, la segmentación del relato, del que solo se obtienen retazos, y la recomposición incompleta y apenas esbozada del pasado de los personajes configuran una aproximación indirecta a la historia.

En ese marco, el espectador ocupa un lugar de desinformación que intenta compensar mediante una serie de operaciones: intuir, adivinar, sospechar. La incomodidad derivada de la ausencia de información conduce a los espectadores a explorar estrategias para descubrir, sobre las superficies sensoriales, aquello a lo que no se accede de manera inmediata. La crisis de la pareja joven de Mar también se narra en estos términos. El espectador desarrolla un sistema de detección de aquellas miradas, gestos, roces, silencios, susurros, que construyen la atmósfera a cargo de contar la historia. En esta dirección, Valeria de los Ríos (2018) apunta la inclinación en el cine chileno reciente a acentuar la relevancia narrativa de la sensorialidad. La captación de las escuchas, los olores, los gustos y las texturas rivalizan con el predominio asignado tradicionalmente a la visión. Este desplazamiento coincide con la relevancia atribuida a las construcciones de lo sensorial en los estudios sobre cine de las últimas décadas. A partir del cuestionamiento de la preponderancia detentada tradicionalmente por la visión, irrumpe una valoración del carácter multisensorial de lo cinematográfico. En este contexto, la recuperación llevada adelante por Gilles Deleuze, en su trabajo sobre Francis Bacon, de la noción de "lo háptico" propuesta por Alöis Riegl para estudiar el arte industrial romano tardío propició la emergencia de numerosos estudios sobre el cine desde esa perspectiva y una transformación de los modos en los que se concibe la sensorialidad en la imagen y el sonido en el cine. Carolina Urrutia sugiere al respecto que "Dominga Sotomayor filma relaciones: amorosas, familiares, de amigos, de hermanos, y lo hace siempre concentrándose en su superficie, en lo que se hace visible desde afuera, guiando la mirada del espectador por un trayecto en cuyo final nada se

\footnotetext{
2 La categoría elaborada por Urrutia no se propone como una clave de análisis del conjunto del cine chileno del período estudiado (2005-2010), sino como un concepto a partir del cual explorar un grupo de películas representativas de determinados giros estéticos, narrativos e ideológicos. A la autora le interesa pensar la pertenencia generacional de estos autores, nacidos entre la década 1970 y mediados de la de 1980 (Sotomayor nació en 1985), sin subsumirlos en una posición homogénea. Al respecto, precisa que este cine "no obedece a un proyecto o a un movimiento común, [sino] más bien a una tendencia relacionada con ciertos antecedentes tecnológicos, productivos, ideológicos y estéticos que permiten su surgimiento e instalación en el panorama audiovisual actual. En términos argumentales, son todos filmes que priorizan la cotidianeidad, desde las estéticas de la alusión, de la levedad, de la trivialidad, de la intimidad" (Urrutia, 2013: 126).
} 
esclarece" (2015). Las aventuras a baja intensidad narradas por Sotomayor posicionan al espectador como el único locus en el que los indicios pueden articularse para recomponer los fragmentos de historias.

De este modo, los primeros films de Sotomayor configuran sistemas de registro de la intimidad. La relevancia detentada por esta en la actualidad del cine chileno llevó a Carlos Saavedra (2013) a proponer considerarla como un nuevo y expansivo género cinematográfico. A su vez, en esta recurrencia puede evidenciarse su posible conversión en un campo donde se proyecta la relación del individuo con su entorno (Barraza, 2018: 23). Así, en el interior del vehículo, durante el viaje en De jueves a domingo, se produce una desdiferenciación progresiva entre el adentro y el afuera en la que al espacio público se pliega la intimidad de la familia. Asimismo, la estadía en el hotel en Mar supone cierta invasión de la intimidad por parte de los ajenos a la crisis de pareja.

Estas reclusiones cinematográficas en la intimidad señalan una ruptura contundente tanto con el cine chileno (y en gran medida latinoamericano) de los sesenta como de los noventa. Urrutia (2013) indica al respecto la ausencia de determinados rasgos definitorios de aquel cine: no hay masa, no hay pueblo, no hay comunidad, no hay ciudad. Estas categorías, articuladoras de ciertas concepciones del cine social, se desvanecen de la imagen y pierden relevancia en la narrativa. Los desplazamientos operados en la dirección que conduce de lo colectivo a lo individual y de lo público a lo privado promovieron una serie de debates en torno a sus perspectivas políticas. En esta dirección, el sintagma "novísimo cine chileno", propuesto por Ascanio Cavallo y Gonzalo Maza en un libro en el que compilan artículos de diversos críticos sobre algunos de los cineastas más relevantes de esta generación, remite justamente a la necesidad de promover una diferencia en relación con el fenómeno del nuevo cine de los años sesenta. De este modo, la recurrencia a la hipérbole vincula con, y al mismo tiempo separa de, ese movimiento político-cinematográfico. En su exploración, Cavallo y Maza identifican como rasgo constitutivo de este novísimo cine la preocupación por el espacio íntimo como territorio de conflicto (2011: 15). Esta elección fomenta, al mismo tiempo, un notorio alejamiento del cine de los noventa, centrado en la voluntad de visibilizar de una manera lineal y frontal las consecuencias de la dictadura y de la implementación del modelo neoliberal.

Carlos Saavedra (2013) piensa esta priorización de lo íntimo en relación directa con la autoafirmación de la ideología del individuo que la globalización reclama como género e identidad. En su argumentación, la conservación del modelo neoliberal implementado durante la dictadura impulsó, en todos los órdenes, este corrimiento de la masa al sujeto. En este desvío se consolidó una modalidad de construcción de la subjetividad definido por la hegemonía de la mercancía, el elogio del hedonismo, el escape de los peligros percibidos en el espacio público (en especial por las clases medias). Si bien las siete películas analizadas por Saavedra ${ }^{3}$ conforman un muestrario de las vidas desencantadas de los protagonistas ante la modernización neoliberal, para el autor estas validan política y estéticamente un escenario socio-cultural concebido como

\footnotetext{
3 Se trata de Play (Alicia Scherson, 2005), En la cama (Matías Bize, 2005), El cielo, la tierra y la lluvia (José Luis Torres Leiva, 2008), Se arrienda (Alberto Fuguet, 2005), La vida de los peces (Matías Bize, 2010), Navidad (Sebastián Lelio, 2009) y La buena vida (Andrés Wood, 2008).
} 
irreversible. La intimidad configurada allí sería una forma de escape ante los dilemas derivados del pasado dictatorial y la supervivencia de las políticas neoliberales.

El posicionamiento melancólico de Saavedra, anhelante del cine social de los años sesenta y de la participación de las masas como sujeto político y como protagonista de los relatos, no coincide con la perspectiva planteada por Vania Barraza. Si bien Barraza también sitúa al cine chileno reciente en clara ruptura con los antecedentes del cine militante (por su desconfianza de las metanarrativas, su postulación de una muy limitada participación del Estado y su descreimiento de los proyectos colectivos como ejes del cambio social), inscribe la renovación cinematográfica operada a partir del 2000 en el marco de las políticas del desapego del Chile de la postdictadura. En ese contexto "aquellas creaciones dominadas por una imagen subjetiva, contemplativa, cosmopolita y/o desvinculada de un pasado que aún le pesa (o le pena) a la sociedad chilena, se organizan en torno a una contención emocional, extrañeza o desapego con respecto al contexto social donde se producen” (Barraza, 2018: 37).

A partir de esta vinculación con la historia reciente y sus reverberaciones contemporáneas, resulta posible establecer el doble desafío al que se enfrenta el cine chileno: asumir la historia evadiendo los modos remanentes del cine militante; asumir los embates del neoliberalismo en el presente evitando los recursos cristalizados del realismo denuncialista de los años noventa 4 . Frente a estas dificultades, "un significativo número de estas producciones ofrece agudas lecturas críticas sobre el autoritarismo militar y la transición democrática que le sigue, al proyectar, de manera indirecta, los efectos del neoliberalismo en la sociedad chilena contemporánea, revalidando, así, una concepción de cine social5" (Barraza, 2018: 15). En este sentido, la intimidad no se concibe como opuesta a lo público y lo colectivo, sino como el territorio sobre el que se proyectan las consecuencias de la historia y se imprimen los dilemas promovidos por el modelo neoliberal. El cine de lo íntimo no sería una renuncia ante el necesario abordaje de las huellas del pasado y las disyuntivas del presente, sino una travesía oblicua para llegar allí.

Esta intimidad, clave en las composiciones de De jueves a domingo y Mar, puede resultar, a su vez, complejizada para narrar otras historias: aquellas en las que se imprime la incandescencia del presente o en las que se pegan las cenizas del pasado de una manera más precisa. En esta dirección, Carolina Urrutia explora la emergencia de nuevas formas de politicidad en ciertas torsiones del cine chileno reciente. Una de ellas la constituye la representación desviada de determinados momentos históricos marcados por acontecimientos propiamente políticos (Urrutia, 2013: 123). El abordaje de la historia a través de estas perspectivas oblicuas resulta una de las claves de Tarde para morir joven. Allí, Sotomayor radicaliza algunas de las búsquedas

\footnotetext{
4 Barraza señala otra dimensión a tener en cuenta, desde la perspectiva de las propias condiciones de producción: "un cine personal, contemplativo, dislocado, indiferente a formar una industria aparece como una forma de resistencia al modelo de producción que rige el nuevo siglo" (2018: 39). Allí se jugaría otra manera de polemizar con el neoliberalismo sin que esto forme parte del plano narrativo explícito de las películas.

5 Asimismo, Barraza señala una diferencia significativa en el marco del cine documental: aquí se extiende el rodaje de documentales desde la perspectiva de las experiencias vividas por los cineastas durante sus infancias. Así, se explora el enlace de la memoria, la subjetividad y la historia (personal, familiar, nacional). Barraza sugiere que, dado que el debate sobre el régimen militar quedó restringido dentro del espacio doméstico, el discurso experiencial sobre la dictadura se transmite en el ámbito de lo íntimo y lo privado. De allí deriva una mirada antiépica, intrahistórica y personal sobre el período (2018: 67).
} 
emprendidas en sus películas previas, pero las imbrica con una inmersión indirecta en un período complejo del pasado chileno: la transición democrática.

En consonancia con las experiencias anteriores, también aquí el espectador es confrontado con la dificultad de asignar sentido a los fragmentos de historia a los que accede. En esta ocasión, sin embargo, se acentúa el carácter dispersivo de la puesta en escena y la consecuente búsqueda de indicios para descifrar la acción. La disgregación se incrementa en relación directa con las vidas dispersivas de los personajes, fundadores de una comunidad ecológica. En esa dispersión, el registro de la vegetación se impone al de los protagonistas, la captación de los objetos desplaza la de los rostros, la escucha de la música sustituye la de los diálogos. Si ya en sus películas previas Sotomayor construía una poética de lo sensorial, en este caso deviene una poética de la materia (en un despliegue en el que se superponen el follaje, los animales, los árboles y los cuerpos). La película aprehende lo tangible y descubre allí el ingreso no solo a los vínculos afectivos ${ }^{6}$, sino también a los lazos comunitarios, las diferencias de clase y los combates generacionales.

La falta de énfasis en la mostración de los elementos que podrían definir el contexto histórico-político (en ocasiones delegada a la música diegética que escuchan o interpretan los personajes) promueve una forma también oblicua de narrar el pasado ${ }^{7}$. En ese universo semicerrado de la comunidad se reproducen las contradicciones de la postdictadura. Sus dilemas (las batallas ideológicas y culturales, pero también simbólicas y narrativas) no aparecen planteados en los términos de la macro-política, ni a través de referencias explícitas a la violencia del terrorismo de Estado o a las consecuencias de la implementación del modelo neoliberal. El abordaje se plantea a partir de un espacio mínimo: esa comunidad concebida como utopía programada. Esta construcción colectiva puede pensarse como una comunidad fundacional: "la condición pionera de una colonia ilustrada, de una avanzada burguesa de la resistencia técnica, que se funda por sobre o de espaldas a la ciudad caótica, y que se quema como las penitencias que debe enfrentar una racionalidad alterna" (Corro, 2019: 1). Sin embargo, esa comunidad no se instituye tanto como el anticipo de una utopía por construirse sino como el resto de una utopía en retirada.

Si bien la definición de comunidad suele sostenerse sobre la idea de una expulsión del afuera y la construcción ficticia de un mundo total, no obstante este deseo, los límites que se quieren férreos pueden ser vaporosos y el afuera que se quiere desterrar puede haber sido incorporado. En esta dirección, los espacios de la comunidad de Tarde para morir joven se presentan como permeables. Las paredes inconclusas se complementan con trozos de plástico, las vacas se pasean por los livings, las casas de madera de los niños no tienen muros, las puertas y ventanas

\footnotetext{
${ }^{6}$ Una perspectiva alternativa para analizar las películas de Sotomayor sería la propuesta desde el marco teórico del giro afectivo. La relevancia y los efectos propiciados por su irrupción en las últimas décadas no pueden desconocerse. Más allá de los aportes centrales realizados por Laurent Berlant, Ann Cvetkovich, Eve Kosofsky Sedgwick, Brian Massumi o Sara Ahmed, en la muy vasta bibliografía que analiza el cine latinoamericano desde este posicionamiento resultan fundamentales The Politics of Affect and Emotion in Contemporary Latin American Cinema: Agentina, Brazil, Cuba, and Mexico de Laura Podalsky (2011), Geografias afectivas: desplazamientos, prácticas espaciales y formas de estar juntos en el cine de Argentina, Chile y Brasil (2002-2017) de Irene Depetris Chauvin (2019), Afectos, bistoria y cultura visual de Irene Depetris Chauvin y Natalia Taccetta (2019), Afetos, relações e encontros com flmes brasileiros contemporáneos de Denilson Lopes ((2016).

${ }^{7}$ Este rechazo al tratamiento épico conforma una de las características de las "poéticas débiles" estudiadas por Pablo Corro (2012) en el cine latinoamericano contemporáneo.
} 
están siempre abiertas y muchas de ellas no tienen vidrios. Esta porosidad espacial replica la de una construcción socio-cultural que pretende fundirse en la naturaleza. Los contornos, sin embargo, constituyen un conflicto cuando señalan la expulsión del mundo circundante que insiste en inmiscuirse de todos modos. Las periferias pobres de la ciudad, recluida en el fuera de campo, se introducen en la comunidad marcando su permeabilidad. Esa comunidad fundacional no logra desactivar el contacto mediado con los entornos que se quiere evadir.

En esa comunidad, la historia se encarna en los vínculos filiales ${ }^{8}$. Los jóvenes desafían los mandatos familiares y evidencian su escepticismo ante el proyecto utópico construido por los adultos (una huida del mundo del terror neoliberal que busca configurar un modo de vida que parece una contracara de aquel, pero que termina coincidiendo en más de un aspecto). Si el proyecto constituye una forma de escape (tanto en el tiempo como en el espacio), los jóvenes ponen en escena su propia pérdida de las ilusiones. Corro (2019) señala al respecto que el cuestionamiento de la inteligencia de los adultos, su coherencia moral y su aptitud constructiva contrasta con la necesidad y la autonomía de los adolescentes. Los jóvenes desamparados se convierten en los voceros silenciosos del desencanto ante el fracaso de los programas utópicos emprendidos por las generaciones previas ${ }^{9}$. En este sentido, si bien la intimidad continúa siendo un aspecto clave de Tarde para morir joven, se trata de una intimidad atravesada por lo público y colectivo, por la historia y la política, por la materia y la filiación. En la travesía recorrida por las películas de Sotomayor, esta perspectiva oblicua se desplaza entre lo íntimo y la historia, priorizando en todos los casos la relevancia de las nuevas generaciones y el valor del paisaje.

\section{FORMAS DESFAMILIARIZADAS DE LA VIDA (FAMILIAR) EN COMÚN}

Los dos largos principales de Dominga Sotomayor transcurren en períodos y espacios de excepción. Un viaje familiar de fin de semana en auto y las vacaciones de verano en la comunidad enmarcan el reordenamiento de las relaciones familiares y el tránsito subjetivo de las protagonistas modelado por ese género que en inglés se llama "coming of age". Preservamos ese nombre a pesar de que existe una versión en nuestra lengua, "relato de aprendizaje", porque implica una diferencia enorme en el contenido de la experiencia ${ }^{10}$. No importa lo que aprende Lucía en De jueves a domingo o Sofía en Tarde para morir joven; es probable que ni siquiera aprendan algo. Lo que ellas atraviesan es un pasaje en el sentido que el término tiene en "ritual de pasaje". Las protagonistas son atravesadas por una serie de experiencias -que tienen que ver con la

\footnotetext{
8 Cavallo, Douzet y Rodríguez (2007) proponen la posibilidad de historizar el cine chileno a través de las representaciones paternas que hayan provisto. Así, se sucederían "el padre benevolente (y caótico) de la Unidad Popular, el padre duro (y ordenado) del régimen militar y el padre reconciliado (y gradualista) de la restauración democrática" (2007: 43). En Tarde para morir joven se quiebra esa percepción reconciliada del padre de la transición.

${ }^{9}$ Este desafío generacional también puede pensarse en relación con el posicionamiento adoptado por los cineastas contemporáneos en contraste con los realizadores de las generaciones de los años sesenta y noventa.

10 Por ejemplo, Dufays $(2014 ; 2016)$ ha trabajado el relato de aprendizaje centrado en personajes niños como alegoría nacional en el cine argentino contemporáneo. Coming of age, por estar arraigado en otras cinematografías, en cambio, no carga con el peso de la referencia contextual obligatoria y se presta para establecer relaciones más flexibles u oblicuas, como las que planteamos aquí.
} 
interrupción del ritmo cotidiano y la organización familiar habituales- de las que salen transformadas: crecen, dejan una etapa para pasar a otra.

El planteo está definido en el comienzo de las dos películas. En la primera imagen de De jueves a domingo, Lucía duerme contra el ventanal a través del que se ven los preparativos del viaje. La secuencia termina cuando el padre literalmente arranca a Lucía de la cama. Esta escena marca la doble ruptura espacio-temporal: durante el período que indica el título la familia cambia la casa por el nomadismo de fin de semana -el período semanal de excepción- en el auto primero y en la carpa después. La precariedad de los dos espacios rompe con el orden familiar que acoge la solidez de la casa. Mucho de esta reorganización, así como de la que experimenta la subjetividad de Lucía, es visible en las secuencias que ocurren dentro o alrededor del auto. El medio de transporte organiza los cuerpos en el espacio, es la forma visual de la posición que ocupan y las relaciones que establecen en el orden familiar.

La segunda escena de la película es de este tipo y define el punto de partida. En el auto, Lucía y su hermano comparten el asiento de atrás. Los padres permanecen fuera de campo, pero se escuchan sus voces. El centro es la niña y la película se ocupa de encuadrarla desde todas las perspectivas disponibles: vista desde afuera por la ventanilla, desde el asiento de adelante, desde la luneta y a través de una subjetiva en la que su mirada capta el paisaje. Ella es el centro de esta historia, pero forma parte del orden que queda establecido en la imagen final de la secuencia: los cuatro miembros de la familia organizada dentro del auto según un orden jerárquico que pone al padre al volante, a la madre al lado y a los niños atrás. Después, todo será movilidad.

Tarde para morir joven también empieza en el asiento de atrás de un auto con niños y voces fuera de cuadro. Es el último día de escuela y por lo tanto el portal hacia el período de excepción vacacional -como una variante larga del fin de semana. La diferencia principal es que lo que se arma arriba del auto a medida que suben otros escolares no es una familia tipo como en la película anterior sino una pequeña comunidad que es el modelo a escala de la organización social que ensayan los personajes de esta película. Es decir, la diferencia entre los autos iniciales es la que sostienen los grupos que protagonizan las películas y los espacios que habitan: la comunidad -como espacio y forma de habitarlo- reemplaza al campamento familiar.

La primera escena, además, establece verbalmente la disputa definitoria del orden familiar y la posición de sus miembros en las dos películas cuando uno de los niños reclama: "a mí me tocaba adelante". Diferentes variantes de la frase o la usurpación directa del espacio que en $D e$ jueves a domingo define el lugar de los padres es uno de los significantes visuales del tránsito de las protagonistas. Lucía ensaya el abandono de la niñez con sus movimientos dentro del auto. Cuando el hermano menor hace un capricho porque quiere ir a la playa, la madre pasa hacia atrás para calmarlo y Lucía asciende a la madurez del asiento de adelante en el que se la ve sonreír sentada bien erguida bajo la presión del cinturón de seguridad que no existe atrás, donde el movimiento de los cuerpos infantiles está menos pautado -el hermano viaja acostado o cabeza abajo, por ejemplo. Lucía deja lo más infantil de la niñez, pero el punto de llegada es indeterminado. De acuerdo con el padre, no puede aprender a manejar porque es un "poroto todavía" pero más adelante es "muy grande" para jugar a hacerlo subida a upa como el menor. En la disputa por la posición dentro del auto, la película define la adolescencia como estado 
intermedio. La niñez queda literalmente atrás pero el pasaje hacia la siguiente etapa es intermitente y está regulado por la autoridad de los padres que hacia el final del viaje y de la película admiten que Lucía tenga su primera experiencia al volante, pero mientras el auto no está en marcha. Son ellos los que empujan el auto, conservan el control sobre su tránsito y el de la hija.

Sofía está en esa edad intermedia y en pugna por abandonarla en Tarde para morir joven. El tránsito hacia lo que podría llamarse juventud pasa también por las disputas en torno a las posiciones dentro del auto, pero también por la variación de los medios de transporte. Los adolescentes Sofía y Lucas reclaman el acceso al volante. Bajo el control paterno, ella puede hacerlo solo en el camino de tierra en el acceso a la comunidad. El avance sobre esos límites espaciales y normativos ocurre en simultáneo al otro avance que tiene que ver con cambiar al novio de la adolescencia por el joven que viene de afuera, Ignacio. Los dos ritos de pasaje se superponen en una secuencia que empieza con la primera salida a la ruta sin la presencia del padre ni de sus límites con el primer beso entre Sofía e Ignacio. Entre la escapada y el beso, el encuentro frente a frente con el auto de juguete que maneja un niño marca la distancia que instalan las nuevas experiencias.

Esta es la segunda relación entre etapas y medios de transporte: los niños tienen bicicletas (o un auto de juguete) y los adultos, autos que los adolescentes reclaman. Ignacio, el joven, tiene moto. Él abre la posibilidad de una nueva edad entre la adolescencia y la adultez hacia la que Sofía avanza cuando se sube con él a la moto y deja atrás el fogón de adolescentes armados de guitarras y vino en caja. En esta película, ser joven es separarse de un grupo. Por el hecho de que transcurre en una comunidad que multiplica el número de familias, Tarde para morir joven también define las etapas y sus relaciones en las formas espaciales que adoptan los grupos de edad: los niños van siempre en una banda desordenada, los adolescentes se reúnen en ronda frente al fogón o en torno a la guitarra, los adultos usan la misma disposición espacial con un propósito definido que falta en la otra: la ronda de los mayores es una asamblea en la que se toman decisiones de las que Sofía y Lucas participan solo desde una posición periférica fuera del círculo. Ignacio, en cambio, está solo o, a lo sumo, de a dos: con un amigo que lo visita y con Sofía.

La juventud no produce grupos, sino parejas. Detrás de él, Sofía actúa su tránsito hacia la próxima etapa. Literalmente, la juventud se define en el recorrido de la moto por la ruta en el que Ignacio maneja y ella lo abraza desde atrás. El pasaje siempre está impulsado por otro que acá es el hombre joven -lo que por supuesto implica relaciones de género tan atravesadas por el poder como la autoridad de los padres que regulaba el tránsito de Lucía. Sofía deja la banda adolescente y al novio de siempre; en la primera escena que comparten, que es la segunda de la película, Lucas y Sofía sueñan con un futuro definido por esa escisión: él quiere vivir solo y ella, dejar la comunidad. El sueño de emancipación individual es la forma en que la nueva generación reacciona contra el proyecto utópico de los padres que refunda en la década de los 90 la aspiración comunitaria de la juventud de la generación anterior. Para Sofía, cambiar ese espacio que está bajo la órbita paterna por Ñuñoa, donde vive la madre, es un proyecto personal en el que se confunden varios objetos de deseo: la independencia, un vínculo que experimenta como falta y una forma diferente de vida. Los primeros dos, estrictamente personales, definen una etapa incierta en que crecer y anhelar el cobijo materno son posibles a la vez; de la misma manera en 
que la resolución clásica del pasaje con el encuentro sexual entre Sofía e Ignacio se complementa con el gesto paterno de abrigarla con su camisa cuando la encuentra a la mañana siguiente.

En De jueves a domingo, los vínculos también se definen en la organización espacial según la posición que ocupa cada uno en las escenas que muestran al grupo completo. La distribución de los cuerpos también establece la organización familiar hacia adentro de la que se define el orden generacional. La disposición en el auto es, por supuesto, central. Pero entre el auto al comienzo del viaje y la vuelta al orden del final, que se expresa en la recolocación en las posiciones atrásadelante convencionales, se sitúa el período excepcional -de jueves a domingo- en que los cuerpos rotan de posición. En un lugar de tránsito, la estación de servicio sobre la ruta, la madre se aparta del grupo familiar para saludar a alguien que viene en otro vehículo con otra familia; el núcleo se abre y los elementos se combinan.

Ese movimiento introduce al menos un aspecto del conflicto que va a desarrollar la película. La ruptura del vínculo entre la madre y el padre empieza como una desorganización espacial de los cuerpos y continúa de la misma manera en el camping, que también es un orden diferente al de la casa que dejaron o el auto donde cada uno tiene una posición establecida. En la mesa compartida, las dos familias se reorganizan de tal manera que sobre un vértice quedan los tres niños y en el otro los tres adultos que componen en la imagen, como en la trama, un triángulo. Lo mismo con las carpas que alternativamente separan a los niños adentro con los adultos que permanecen afuera; al padre que se queda dentro con los niños de la madre que se queda con el otro, primero afuera y después en su carpa. La circulación entre carpas es la desorganización familiar permitida en el tiempo alterno del fin de semana y el espacio transitorio del campamento. Correlativamente, cuando hacia el final de la película vuelven al auto se cancela la posibilidad de explorar posiciones: Lucía ya no puede subirse al techo y los cuatro regresan al orden familiar ocupando el lugar que les corresponde.

Además de los cuerpos que intercambian posiciones, entre los grupos circula la mirada como ejercicio de deseo. Las dos películas de Sotomayor, aunque sobre todo De jueves a domingo, trabajan con puntos de vista oscilantes que abren diferentes perspectivas. Ese recurso interviene en la construcción de estas subjetividades en tránsito. Lucía espía a su madre y al mundo adulto en general, así descubre el desarreglo que se produce en la circulación entre carpas. Pero quizás la distancia entre mundos que define su pasaje a la adolescencia sea una exploración poco convencional de la perspectiva en la que un plano subjetivo muestra a los padres cabeza abajo, vistos por Lucía que descuelga su cabeza por el parabrisas desde el techo del auto. La inversión de la imagen señala la incomprensión del conflicto adulto al que se le niega el acceso aunque tenga la capacidad de registrarlo, una posición ambigua que define el pasaje de Lucía de la niñez a la adolescencia como un dislocamiento de la mirada.

En Tarde para morir joven, una escena análoga, aunque más convencional en su concreción, muestra a dos mujeres de la comunidad fuera de foco, bajo la mirada de la recién llegada Sofía a quien la cámara capta desde la nuca. Igual que los grupos, las miradas se multiplican en esta película. Si la anterior señala solo la distancia, hay otras que agregan curiosidad y deseo por la etapa siguiente: Sofía espía el encuentro de Ignacio con su amigo a través de unos troncos igual que Clara, la más grande del grupo de niños, la mira a ella con él en la fiesta de año nuevo. El 
deseo de crecer y cambiar de etapa está en la voluntad de conquistar espacios reservados a los más grandes que se expresa en una mirada oblicua, que se esconde para curiosear en estos tiempos y espacios abiertos a la experimentación. Al principio del documental Ultimas conversas (2015), que terminaron después de su muerte la montajista Jordana Berg y João Moreira Salles, Eduardo Coutinho se queja de que la película, estructurada como una serie de diálogos en línea con sus trabajos inmediatamente anteriores, es imposible porque los adolescentes no tienen nada que decir. Sotomayor resuelve ese mutismo cargando de expresividad la corporalidad. Las ganas de crecer no se dicen, sino que se actúan, el pasaje se cuenta como movimiento de los personajes y la cámara. Las películas exploran la capacidad del punto de vista y la organización de los cuerpos en el espacio para dar cuenta de esas experiencias.

\section{FUERA DE LUGAR O AFUERA EN ALGÚN LUGAR}

Los personajes de los largos de Dominga Sotomayor circulan y ocupan entornos naturales, que se convierten tanto en condensadores de deseos como en evidencia de derrotas y frustraciones. Pensar la manera en que aparece el paisaje en estos films implica establecer algún tipo de relación entre esos sujetos y su historia.

El paisaje es el gran articulador entre aquello que llamamos naturaleza y eso otro que denominamos cultura. Si durante siglos se lo entendió como un espacio controlado por Dios, después se volvió el resultado de la acción y la mirada del hombre sobre el territorio y encontró justificaciones políticas, éticas y estéticas. El paisaje es una apropiación simbólica que los grupos y las clases hacen de ese "lugar común" (Silvestri, 2011) porque es allí donde se realizan buena parte de las acciones sociales y funciona la vida colectiva. Todo paisaje es al mismo tiempo objeto y medio a través del cual la lucha por el control tiene lugar, donde florecen las estrategias espaciales de dominación y resistencia (Andermann, 2008).

¿Qué esperan Martín (Mar), la pareja de padres (De jueves a domingo) o la comunidad que vive en la reserva ecológica de Peñalolén (Tarde para morir joven) de la naturaleza? ¿Qué van a buscar allí? Diríamos, en principio, vacaciones y descanso, una escapada familiar donde el tiempo compartido cure ciertas asperezas, una forma de vida alejada del consumismo y de los valores corruptos del capitalismo. ¿Y qué encuentran?

Jens Andermann (2008) propone pensar al paisaje como el proceso que va de la imagen al entorno y viceversa, ensamblando lo humano con lo no-humano. Siguiendo esa línea intentaremos señalar algunas cuestiones en los films que articulen la mirada, el entorno y el vínculo que establecen los personajes con aquello que llaman "la naturaleza" y que se presenta, a veces, como "paisaje".

En Mar la relación con la naturaleza se observa inmediatamente, el título hace alusión al océano y también al nombre del protagonista Martín (al que llaman Mar). Esta alianza entre ambos será retomada de distintas maneras: Martín es el único que se baña en el mar (ni su novia, ni su madre lo hacen) o queda dicho explícitamente en el diálogo que tiene con un niño en el balneario. Cuando este le pregunta por qué está triste, Martín le responde que la novia lo dejó: "me abandonó, se fue para otra playa, para otro mar". 
El mar es lo que condensa buena parte de lo que llamamos naturaleza en este film. En él se vuelcan varias de las expectativas que reconocemos propias de la clase media, para la cual suele estar vinculado con: la playa, las vacaciones, el verano, el placer, la aventura y la posibilidad de salir de la rutina. Sin embargo, esa promesa de felicidad enseguida se ve abortada. El film comienza con un problema técnico del auto que, sumado a la falta de papeles, provoca una primera discusión del protagonista con la madre y también con su novia. Pero más adelante aparecerán los cuestionamientos acerca de la paternidad, las preguntas difíciles, los desencuentros amorosos, la muerte, el robo, el aburrimiento, las peleas, la enfermedad. Nada de esto está asociado a la idea de "vacaciones en el mar". Las tomas descentradas, los cuerpos parcialmente fuera de plano, recortados por el borde del marco, dejan ver el entorno: la arena, el agua, la pileta. Escenarios naturales donde los protagonistas tratan de "encajar", a veces sin demasiada suerte.

Hacia el final de Mar también aparece el fuego. La quema del auto se inscribe en la conflictiva relación que Martin tiene con su madre ¿Lo quema porque la madre se lo pidió? ¿Es su modo de ayudarla? ¿Es una manera de poner en evidencia que no escapamos a los conflictos que heredamos de nuestros padres? Quizás todo eso, que además se impone como el germen de una idea que la directora retomará con fuerza en Tarde para morir joven.

En De jueves a domingo el entorno natural está fuertemente limitado y señalado por los marcos de las ventanas. Pocos dispositivos están tan vinculados a nuestra idea de cuadro y paisaje como este. En su tratado De Pictura (1435) Leon Battista Alberti habla del cuadro como una ventana "a través de la cual nos parezca estar viendo el espacio". Este espacio ya no daría cuenta de su condición material, sino que se transformaría en un "plano figurativo". Pero Alberti no solo usó la ventana como metáfora de la representación pictórica renacentista, también utilizó un marco con una rejilla para buscar puntos de referencia espaciales y llevarlos al papel mediante una cuadrícula a escala. Algo similar a esta cuadrícula podemos reconocer en los vidrios repartidos de la ventana de la habitación de los niños, desde la cual vemos el auto en el jardín y a los padres haciendo los últimos preparativos para el viaje. El film se abre entonces marcando la diferencia entre el afuera y el adentro y el límite entre ambos espacios se corporiza en el marco de una ventana.

Vendrán otras ventanas con protagonismo a lo largo del periplo: las del auto. Las ventanillas no ofrecen un paisaje estático, ordenado según la perspectiva artificial, sino la vista limitada de un exterior en movimiento. Lo mismo observó Jacques Aumont (1997) en relación con el ferrocarril, entendiéndolo como una máquina fundacional de la condición moderna de mirar. Una mirada que recorta y dinamiza el mundo que está allá afuera. La misma que después se encarnará en el cine. La ventana hace de esa inmensidad caótica, infinita y desmesurada que es la 
naturaleza un espacio recortado, abarcable, observable y al alcance del ser humano que es el paisaje ${ }^{11}$.

Y otra vez la pregunta ¿Es bueno o malo vivir/ estar/ transitar la naturaleza? Acá también hay ciertas esperanzas que se ven truncadas: el auto se queda estancado en el barro, los cerdos invaden la zona de los campantes, la vida a la intemperie puede resultar un tanto incómoda. Pero sobre todo el aire libre, los lagos y el bosque no serán suficientes para solucionar el conflicto y el desamor entre los padres.

La relevancia que adquiere la sensorialidad se acentúa especialmente en el plano sonoro. La naturaleza no solo se transita o se ve, también se escucha: el ruido del agua, del viento, el croar de los sapos y los grillos funcionan como "enemigos" de la curiosidad de Lucía cuando no le permiten escuchar las conversaciones de la madre y Jorge en el río o los ruidos (¿jadeos?) que provienen de la carpa de al lado.

Como se mencionó anteriormente los espacios híbridos (donde conviven el adentro y el afuera y se tocan lo público con lo privado) son frecuentes en los films de Sotomayor. La carpa con sus "paredes" de tul, blandas y transparentes, el automóvil que sirve como vehículo y cama, la casa rodante donde se come afuera, son algunos ejemplos de este espacio permeable al escenario natural.

Pero es en Tarde para morir joven donde la presencia de la naturaleza se vuelve contundente y articula toda relación entre los personajes. ¿Qué expectativas se concentran en ella? Quizás una vida más sana, en comunidad, cerca de la música, el arte, la familia y los amigos y bien lejos del capitalista mundo del consumo.

A diferencia de Mar y De jueves a domingo donde el vínculo y la búsqueda de la naturaleza forman parte de una ruptura con la cotidianeidad (las vacaciones o la escapada de fin de semana) acá estamos invitados a observar la vida diaria de un grupo de familias que viven en comunidad. Como se dijo, el "tiempo especial" es para los niños, que comienzan sus vacaciones de verano, para el resto de la comunidad las actividades, los espacios y los vínculos son los del transcurrir cotidiano.

El escenario, y todo lo que encontramos en él, se torna por momentos impreciso. ¿Dónde vive cada familia? Las casas son también talleres y espacios de juego. La variedad de máquinas (autos, motos, motores, bombas de agua, generadores de electricidad, radios) que están desperdigados, fuera y dentro de las habitaciones, están rotos, son viejos o funcionan a medias. Nada sirve del todo, o todo sirve para varias cosas, todo es de ahí, pero también de algún otro

11 En el paisaje, la "segunda naturaleza" (para valernos del concepto lukácsiano) aparece imbricada inexorablemente con la primera que no existe sino como efecto negativo de esta. En rigor, pues, como sugiere Jacques Derrida, "no hay naturaleza, sólo sus efectos". El paisaje representa estos efectos, en el doble sentido propio del concepto de representación. Por un lado, remite a la imagen hecha, al paisaje-visión (y así a la noción de lugar, como orden estable de elementos figurado en el conjunto de líneas y volúmenes que organizan y convierten el marco visual en un todo estéticamente placentero, correspondiente a una sensación de habitabilidad). En cambio, en su sentido performativo, representación remite a la puesta en relación entre cuerpo y entorno, y así a una noción de espacio entendido o bien en términos de rito o ceremonia (como la puesta tanto, nuevamente como producción de lugares) o bien como ensamble móvil y dinámico de interacciones imprevisibles entre agentes humanos y no-humanos (Andermann, 2008). 
lado. Lo mismo se señaló anteriormente respecto a las viviendas, con sus techos, puertas y ventanas construidas a medias. No sabemos si ese mundo está por arreglarse o si ya está fatalmente destruido.

Entonces, ¿hay paisaje posible en estos espacios híbridos e inacabados?

Si las ventanas no separan el interior de la casa del exterior, si no se produce el recorte, el apartamiento de la naturaleza, esta no deviene paisaje. Los personajes están muy cerca, muy adentro, para contemplar. La distancia necesaria entre el espectador y el entorno se anula. La ventana ya no funciona como metáfora de la pintura cuando no es capaz de enmarcar nada digno de ser mirado como espectáculo. El cuadro que le regala la madre de Lucas a los vecinos recién llegados, como ofrenda de bienvenida a la comunidad, deberá esperar a ser colgado "hasta que tengamos pared".

¿De qué otra forma se hace presente en el film la "naturaleza intervenida"? Mediante aquellos elementos que están indisolublemente ligados a ella: el agua, el fuego, el aire, los árboles.

Acá también la naturaleza se torna dimensión sonora. Se escucha en el aire de la comunidad: ladridos de perros, mugidos de vacas, sapos y grillos, el soplar del viento, el correr del agua y el ruido del fuego. Todo esto forma una textura auditiva que construye y da densidad a este entorno particular. Operando en el mismo sentido que De jueves a domingo, el sonido de la naturaleza se activa (sube su intensidad y volumen) para impedir a Clara escuchar lo que dicen Sofía e Ignacio en el auto.

De la variedad de pares dicotómicos que podemos reconocer en Tarde para morir joven (ruralurbano, juventud-madurez, dentro-fuera, comunidad-soledad, amistad-sexualidad) hay uno que nos remite a la potencia de la naturaleza: fuego-agua. El fuego abre y cierra el film. La primera escena nos presenta a un grupo de vecinos quemando basura y a los bomberos apagando la fogata. Después vendrán otros "pequeños fuegos" que nos recuerdan ese primero y nos preparan para el final: cigarrillos, fogatas, velas, cañitas voladoras. También el fuego se menciona en varios comentarios de Lucas: "si prende arriba, cagamos" o en la canción que canta con su banda el día de la fiesta: "Mira cómo se derrite el sol. Dale calor, dale calor..." o: "Voy a quemar las canciones malas que escribí para que no quede registro".

El agua también aparece de manera recurrente y es tema de preocupación de los vecinos: quieren instalar una bomba para prevenir incendios, a las casas les falta agua porque "alguien la cortó" y buscan con ilusión terrenos que tengan agua subterránea. También aparecen "pequeñas aguas" que nos ayudan a anticipar la final: la pileta, la bañera, la ducha, el lago donde las niñas se protegen del incendio.

Estos dos elementos naturales forman parte de los personajes, sus vidas y sus acciones. En la primera escena en la que vemos a Sofía y a Lucas, la cámara los encuentra acostados en el piso, uno sobre el otro, en un juego de amigos, pero no solo eso. El agua y el fuego ya están presentes en este vínculo a través del cigarrillo y la cantimplora. Y volverán en distintas ocasiones como convivencia de opuestos: Sofía fumando en la bañera, el cigarrillo en la caja de vino.

La fiesta de fin de año origina el incendio. El gran fuego de la película. De esta forma se entreteje el fin de una etapa y el comienzo de otra. El fuego produce una tabula rasa sobre la que 
crear un universo nuevo, porque aniquila, pero también cauteriza, porque, a riesgo de consumirlo todo, convoca a todos. Ese fuego redentor se produce en un espacio que era necesario vaciar. El nuevo mundo requiere la desaparición del antiguo.

Este gran fuego final pide ser leído de diversas maneras. Puede abrir un camino hacia la beatificación y otro hacia la hoguera. Puede ser la aniquilación de esa comunidad o la manera de hacer ingresar a Sofía definitivamente en ella. El gran fuego final debe confrontarse, otra vez, con el agua. Ese último baño de Sofía, el bautismo que la inserta en la comunidad, es también el que le permite encontrarse con el padre.

Nada funciona del "todo bien" en las películas de Dominga Sotomayor: ni las parejas, ni los aparatos, ni la seguridad, ni la comunidad, ni el auto, ni la familia, ni las mascotas, ni las fiestas, ni las vacaciones. Ni el adentro, ni el afuera. Si vivir dentro de la comunidad es imposible para Sofía tampoco es muy alentador lo que ocurre fuera de ella. Nadie la busca, nadie la espera, nadie la lleva.

Los personajes no terminan de encontrarse en los espacios que recorren, inventan o habitan y tampoco se hallan cómodos en el tiempo que les toca vivir. Parece que siempre es demasiado temprano o demasiado tarde para todo: fumar, manejar, perdonar, tener hijos, desear, quedarse o escapar.

La escapada final de Frida (o Cindy, será el espectador quien decida qué nombre le va mejor a la perra) produce angustia, pero sobre todo alivio, al igual que ocurre con Sofía parece que llegó el momento de dejar de luchar contra lo inevitable. La perra acerca dos mundos irreconciliables (el de la clase media y el de la clase baja); es la excusa que habilita el contracampo, el espacio que existe fuera de la comunidad y también la que nos conduce hacia una reja que separa, de manera contundente, una forma de vida de la otra. El paisaje también nos enseña eso, a mirar los alrededores.

\section{CONCLUSIONES}

Las películas dirigidas por Sotomayor formalizan una reflexión sobre la mirada. En un corpus definido por la alternancia de recurrencias y desvíos, esta constituye un elemento organizador del espacio, de los vínculos entre los personajes y de las emergencias de la historia. En relación con el espacio, se trata de una mirada permeable que no solo configura el paisaje como territorio híbrido entre la naturaleza y la cultura, sino que señala la exagerada cercanía como punto de imposibilidad para que el paisaje se conciba y funcione como tal. Esa mirada, a su vez, se articula a través del intento de expulsión de los territorios sociales que se consideran ajenos. Sin embargo, la propia permeabilidad espacial introduce, desde el fuera de campo y en sus breves actualizaciones, esos dominios ajenos.

En relación con los vínculos entre los personajes, irrumpe una mirada generacional portada por los niños y los adolescentes. Este sesgo diferencial desnaturaliza los ordenamientos familiares a través de la inclusión de las ideas de tránsito y mutabilidad, pero también mediante la aparición de los conflictos derivados de la ruptura generacional, marcada por el desencanto con la generación previa que organiza desde las relaciones íntimas y familiares una tensión propia del 
mundo histórico al que las películas interpelan. Las miradas de estos niños y adolescentes se dirigen de manera oblicua hacia la historia; no la alegorizan, sino que la convierten en problema de la forma cinematográfica que establece un sistema de registro de la intimidad como un espacio afectivo y material en el que se negocian las tensiones entre lo público y lo privado.

En esta dirección, en la filmografía de Sotomayor se inscribe gran parte de los debates abiertos en el cine chileno, y latinoamericano, contemporáneo en torno a las aproximaciones desviadas a la historia, la búsqueda de nuevas perspectivas narrativas, la elección de los puntos de vista infantiles como generadores del relato, el desmontaje de las apreciaciones cristalizadas del espacio y la naturaleza, la remoción de las formas convencionalizadas de pensar los enlaces del cine y la política. 


\section{BIBLIOGRAFÍA}

AndermanN, Jens. "Paisaje: Imagen, entorno, ensamble”. Orbis Tertius 13-14 (2008).

Aumont, Jacques (1997). El ojo interminable. Barcelona: Paidós.

Barraza, Vania (2018). El cine en Chile (2005-2015). Políticas y poéticas del nuevo siglo. Santiago: Cuarto propio.

Cavallo, Ascanio, Douzet, Pablo, Rodríguez, Cecilia (2007). Huérfanos y perdidos. Relectura del cine chileno de la transición 1990-1999. Santiago: Uqbar.

Contreras Delgado, Camilo. "Pensar el paisaje. Explorando un concepto geográfico". Trayectorias 17 (2005).

Corro Pemjean, Pablo (2012). Retóricas del cine chileno. Ensayos con el realismo. Santiago: Cuarto propio.

Corro Pemjean, Pablo. “Tarde para morir joven”, laFuga 22 (2019).

DUFAYS, Sophie (2014). El niño en el cine argentino de la postdictadura (1983-2008). Alegoría y nostalgia. Sufolk y Rochester: Boydell \& Brewer.

DUFAYS, Sophie (2016). Infancia y melancolía en el cine argentino, de La ciénaga a La rabia. Buenos Aires: Biblos.

DE LOS Ríos ESCOBAR, Valeria. “Cine chileno contemporáneo: cartografía provisoria para un campo en expansión”. Icónica (2018).

MARZO, Jorge Luis (2010). La memoria administrada. Buenos Aires: Akal

SAAVEDra CERDA, Carlos (2013). Intimidades desencantadas. La poética cinematográfica del dos mil. Santiago: Cuarto propio.

SILVESTRI, Graciela (2011). El lugar común. Buenos Aires: Edhasa

SOTOMAYOR, Dominga. "Documentando una realidad provocada”. laFuga 1 (2005).

Sotomayor, Dominga (2012). De jueves a domingo. Chile, Holanda: Forastero, Cinestación, Circe Films.

SOTOMAYOR, Dominga (2014). Mar. Argentina, Chile: Cinestación, Frutacine.

SOTOMAYOR, Dominga (2018). Tarde para morir joven. Chile, Brasil, Argentina, Holanda, Qatar: Cinestación, RT Features, Rude Cine, Circe Films.

UrRUTIA, Carolina (2013). Un cine centrifugo. Ficciones chilenas 2005-2010. Santiago: Cuarto propio.

Urrutia, Carolina. “Mar”. laFuga 17 (2015). 